\title{
Máquina de ver, máquina de visão: sobre usos profanatórios e subjetivações potenciais do Oculus Rift enquanto dispositivo
}

\author{
Ana Maria Vieira Monteiro ${ }^{1}$ \\ Nilson Assunção Alvarenga²
}

\begin{abstract}
Resumo: Diante dos atuais aparelhos de realidade virtual, que vêm ganhando a atenção dos desenvolvedores de jogos e aplicativos diversos, surgiu a necessidade de tomar o mais destacado deles, o Oculus Rift, e situá-lo em um referencial teórico, questionando-o quanto aos seus usos potenciais nas artes. Para tanto, partimos da análise de um campo de forças que atuam nos dispositivos dos quais o Oculus é precursor. Forças essas que, conforme propomos, encontram-se na tensão entre os usos previstos e os usos potenciais, sendo que os últimos, contextualizados no horizonte de uma filosofia do dispositivo, poderiam ser pensados a partir das noções de subjetivação, com Deleuze, e de profanação, com Agamben. No entanto, como buscamos contrapor, são raras as intervenções que atualizam as potências do dispositivo. Enquanto isso, um experimento chamou nossa atenção para o que se busca, com este artigo, trabalhar: modos pelos quais se pode pensar um uso profanatório de headsets de realidade virtual. Concluímos com reflexões sobre como o experimento Gender Swap joga com as forças que perpassam o dispositivo, apontando para potenciais subjetivações que rompem com suas linhas duras.
\end{abstract}

Palavras-chave: Oculus Rift, profanação, subjetivação, Gender Swap Experiment.

\begin{abstract}
Together with the acknowledgement of today's virtual reality devices, which have been gaining the attention of various games and application developers, came the need to take the most prominent of them, the Oculus Rift, and place it in a theoretical framework, raising questions about its potential use in arts. Therefore, our starting point was the analysis of a field of forces that act on the range of devices in which Oculus is the precursor. These forces, as we propose, are seen as the intended use and the potential use. The latter, contextualized in a dispositif philosophy, could find its meaning in Deleuze's idea of subjectivity and in Agamben's view on profanations. However, as we seek to oppose, interventions that update the device's potential are rare. Meanwhile, an experiment called for our attention, taking in consideration what is sought to demonstrate within the limits of this paper: the ways in which one can think of a use for virtual reality headsets in profanation. We conclude by reflecting on the experiment Gender Swap, once it plays with the forces that span the device.
\end{abstract}

Keywords: Oculus Rift, profanation, subjectivation, Gender Swap Experiment.

\section{Introdução}

O lançamento recente de aparelhos de realidade virtual trouxe à tona indagações sobre a arte contemporânea, as quais dizem respeito ao campo de forças que permeiam os dispositivos técnicos, levando a pensar, para além de seus usos previstos, novos potenciais estéticos.

\footnotetext{
${ }^{1}$ Mestre em Comunicação Social pela Universidade Federal de Juiz de Fora (UFJF). E-mail: anamvmonteiro@gmail.com.

${ }^{2}$ Doutor em Filosofia pela PUC-Rio e professor permanente do PPGCOM da UFJF. E-mail: nilsonaa@terra.com.br.
} 
Uma abordagem conceitual possível, tendo-se em vista headsets de realidade virtual como o Oculus Rift (aparelho da empresa de mesmo nome, subsidiária da marca Facebook), poderia ser pensar a experiência propiciada por eles para um ponto além (ou, talvez melhor, aquém) de oposições clássicas entre verdade e simulacro, atual e virtual ou linguagem e dispositivo, pois a própria noção pressuposta aí de real está, de saída, condicionada por certa identificação sujeito-obra em que o significante se constrói a partir de inputs (movimentos físicos do usuário) e o tempo da obra é o tempo real, vivido pelo sujeito nela imerso. Isso porque o propósito de headsets de realidade virtual é possibilitar ao usuário interagir gestualmente com imagens tridimensionais e situá-lo em ambientes virtuais esféricos (o olhar pode ser direcionado para qualquer ângulo, não existindo mais a parte de trás da cena), propiciando, assim, uma experiência estética específica. que privilegie a tomada de ação por parte daquele que se dispõe a ver as imagens e que é, de certa forma, visto por elas.

Situando esta experiência em uma linha de pensamento teórica, poderíamos evocar tanto a noção de um realismo afetivo (cf., por exemplo, Karl Schollhammer, 2012, e Shaviro, 2007a e 2007b) - segundo a qual “a identificação efetivamente existe no momento do acontecimento, existe de uma maneira que se sobrepõe a uma distância subjetiva diante da obra [...]" (SCHOLLHAMMER, 2016) -, quanto uma filosofia do dispositivo, se assim podemos chamá-la - na tradição que parte de Foucault, seguida por Deleuze e Agamben, passando, no caso dos estudos do cinema, por Baudry.

Até o momento, o potencial explorado do dispositivo Oculus Rift aponta não apenas para uma afetividade corporalmente mediada, mas, em uma via de mão dupla, também uma espécie de auto-afetividade, uma vez que as imagens são também condicionadas pelo usuário/espectador ${ }^{3}$. Esse último efeito faz alusão a um potencial por si mesmo afetivo: propiciar a sensação de presença corpórea em mundos virtuais tão vastos quanto a imaginação poderá criar. Um deslocamento que somente poderia ser desbancado pela ideia de teletransporte (se é que os meios de realidade virtual já não são mesmo isso). Nesse contexto, é também válida a observação de $\operatorname{Schollhammer}^{4}$ (2016) a respeito do papel do dispositivo na arte contemporânea: o de ser a própria linguagem da obra de arte., ou seja, criar

${ }^{3}$ Sobre o "usuário-espectador", ver BAIO, 2015.

${ }^{4}$ Autor em entrevista disponível em: <http://www.estacio.br/graduacao/cinema/digitagrama/numero4/ entrevista.asp>. Acesso em: 11 jun. 2016. 
possibilidades de interação"Não porque ela será parte do espetáculo da realidade, mas porque na sua própria vivência, irá criar outras possibilidades de convívio, de interação, de vida". .

Se quisermos, porém, pensar para além dos potenciais já previstos e explorados por esse, dentre outros, dispositivos atuais de realidade virtual, a abordagem deveria ser outra. $\mathrm{O}$ que nos preocupa aqui são as articulações possíveis, no campo de uma filosofia do dispositivo, entre os usos previstos de dispositivos técnicos como o Oculus Rift e os seus usos potenciais, que apontam não somente para o controle de percepções e comportamentos, mas também para linhas de fuga e subjetivação (Deleuze) ou profanações (Agamben).

\section{Oculus Rift enquanto máquina de ver}

Antes de considerarmos as questões relativas aos usos potenciais e a processos potenciais de subjetivação envolvidas nas apropriações do dispositivo Oculus Rift, é preciso que este também seja situado na cadeia de acontecimentos tecnológicos, os quais, ao mesmo tempo em que dizem muito de suas reais potencialidades, também estabelecem seus usos previstos. E é nesta dicotomia, de usos previstos e potenciais que, pensamos, o conceito de dispositivo vem exercer sua maior influência no campo de forças que já atravessa a realidade virtual como um campo fecundo para as artes.

$\mathrm{O}$ headset que tem preconizado essas questões foi idealizado pela empresa Oculus VR desde março de 2014, quando o aparelho ainda era o protótipo DK2 (Development Kit $2)^{5}$. O Oculus Rift, como versão do consumidor (consumer version 1 - figura 1), abriu sua temporada de pré-vendas no dia 6 de janeiro de 2016 para 20 países, ao custo de 599 dólares. E as primeiras encomendas do produto, segundo o blog da Oculus VR, começaram a ser enviadas no dia 28 de março de $2016^{6}$.

Mudanças significativas em relação ao DK2 são a inclusão de um sistema de áudio com fones removíveis incluídos no headset e o dual display de 2160 x 1200 pixels. Além

${ }^{5} \mathrm{Em}$ 2012, a Oculus VR, fundada por Palmer Luckey, lançou sua campanha no site Kickstarter.com para aperfeiçoar o protótipo do Oculus Rift, o DK1 (Development Kit 1), prometido aos doadores de 300 dólares ou mais. Em apenas quatro horas no site, a meta de 250 mil dólares foi alcançada e, no total, a empresa levantou 2 milhões e 400 mil dólares somente via crowdfunding (financiamento coletivo). No ano seguinte, ao custo de 350 dólares, a empresa anunciou o DK2 (Development Kit 2), com diferenças significativas em design, resolução (de 1280 × 800 para 1920 x 1080), e a inclusão de uma câmera de infravermelho, aprimorando a capacidade de rastreamento dos movimentos do usuário e diminuição da latência (o tempo de reação do sistema aos dados de entrada).

${ }^{6}$ Disponível em: <https://www.oculus.com/en-us/blog/oculus-rift-is-shipping/>. Acesso em 29 mar. 2016. 
disso, um dos componente do pacote Oculus Rift é um controle do Xbox One, console da Microsoft.

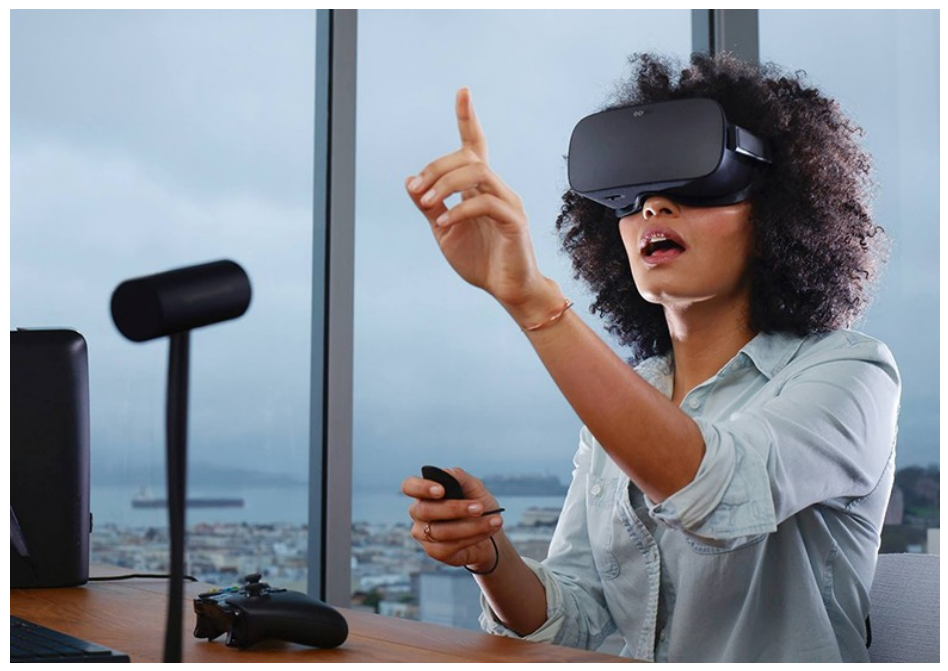

Figura 1 - Campanha de lançamento da primeira versão de consumidor do Oculus Rift. Fonte: Oculus $\mathrm{VR}^{7}$.

Embora os aplicativos para realidade virtual apresentem um grande potencial para a indústria cinematográfica e dos jogos, esses ainda se encontram, em sua maioria, no campo da experimentação e dos aplicativos que acompanham o Oculus Rift, como o Oculus 360 Photos, com o qual explora-se mais de 200 mil destinos.

Se, por um lado, os aspectos tecnológicos da realidade virtual explicam o reavivamento do interesse da indústria por esses meios, por outro, falham em aprofundá-los como máquinas de visão. Portanto, considera-se pertinente a problematização do discurso sobre a novidade do Oculus Rift, ampliando a reflexão sobre seus usos possíveis - e não apenas previstos - por um viés estético. O uso do termo dispositivo para se referir ao Oculus Rift deveria, para isso, levar em conta também a imaterialidade que repousa sobre o meio, as tradições e os agenciamentos visíveis em seus enunciados.

\footnotetext{
${ }^{7}$ Disponível em: $<$ https://www.oculus.com/en-us/blog/oculus-rift-pre-orders-now-open-first-shipments-march-
} 28/>. Acesso em: 5 jun. 2016. 


\section{Oculus Rift enquanto máquina de visão}

Se refizermos a pergunta de Giorgio Agamben (2005) e, antes dele, de Gilles Deleuze (1988) - o que é um dispositivo? -, ambos sob a influência foucaultiana ${ }^{8}$, encontraremos, para além dos sentidos já destacados por esses autores, alguns outros.

Agamben e Deleuze preocupam-se com as relações entre certas configurações ou constelações discursivas, epistêmicas, materiais específicas (arquitetônicas, por exemplo), em um dado momento histórico, de relações de poder. Isso corresponde, na imagem deleuzeana, a linhas de força que sustentam essas relações ou, na conexão conceitual agambeniana, a positividades dessas relações em uma dada sociedade.

Frank Kessler (2007) elenca outros sentidos para além desse foucaultiano. No campo específico dos estudos de cinema, a tradição que remonta a Jean-Louis Baudry ${ }^{9}$ fala de dispositivos de duas maneiras, e Ismail Xavier (2005) sugere falar em dispositivo e Dispositivo. No primeiro sentido, falamos daquilo que, na tradução para a língua inglesa, como apontado por Kessler, seria o apparatus, motivo, inclusive, pelo qual o autor acha problemática a tradução do texto de Baudry. Trata-se, neste caso, do dispositivo como a máquina ou, se quisermos, o meio especifico: o aparelho de registro de imagens e sons - a máquina de ver e ouvir o mundo. É assim também, de certo modo, que o termo aparece na linguagem comum quando falamos de dispositivos móveis, dispositivos elétricos etc.

Para além da máquina de ver, no sentido material, encontramos, no entanto, as máquinas de visão, em um sentido mais alargado e abstrato da visão: o aparelho material conectado a aparelhos ideológicos, para usar a expressão de Louis Althusser, que está na base, junto com o Lacan do Seminário VII, do texto de Baudry. A máquina de ver é também uma máquina de visão porque, por um lado, ela vê conforme uma concepção do olhar, uma concepção que traz consigo uma conotação ideológica que, incorporando em obras específicas

\footnotetext{
${ }^{8}$ Michel Foucault é especialmente relevante como ponto de partida de uma teoria do dispositivo, pois foi ele quem primeiro empregou o termo "dispositif" em um contexto variado de relações de poder entre indivíduos. Curiosamente, não há, na obra do autor, uma conceitualização para "dispositivo", apenas uma comparação deste, formulada durante uma entrevista, a uma rede (réseau) que se pode traçar entre elementos "de um conjunto decididamente heterogêneo que engloba discursos, instituições, organizações arquitetônicas, decisões regulamentares, leis, medidas administrativas, enunciados científicos, proposições filosóficas, morais, filantrópicas. Em suma: o dito e o não dito" (FOUCAULT, [1977] 1994, p. 299). Tão ampla quanto essa descrição é a gama de interpretações sobre o dispositivo que têm Foucault como referência.

${ }^{9} \mathrm{Na}$ década de 1970, Baudry foi quem primeiro ampliou a definição de dispositif para os estudos sobre cinema, na corrente de pensamento que veio a ser chamada de teoria do dispositivo (apparatus theory).
} 
esse olhar de cunho geral, o qual remonta ao perspectivismo renascentista, gera interesse porque desperta no espectador um vínculo de identificação, dada no nível de uma subjetividade que Lacan chamara de um Eu no estádio do espelho. Dispositivo, portanto, no campo do cinema, denota ou a máquina de ver ou os aspectos ideológicos e psicológicos inerentes à máquina de visão.

Esse debate sobre o dispositivo e o Dispositivo e suas implicações, como mostra Xavier, é extenso e, mesmo em suas configurações contemporâneas, está longe de gerar consenso. Interessa aqui, no entanto, um aspecto dessa conexão entre uma máquina de ver específica - o Oculus Rift - e o seu lugar dentro de um horizonte mais amplo, a saber, o modo como ele traduz, incorpora e reinveste uma certa concepção do olhar ou da visão. Para tanto, partimos do pressuposto de que no uso já estabelecido do Oculus Rift está previsto um modo bem específico de uso, ainda que implícito.

Que modo de uso é este? O que está previsto na máquina de ver que traduz um olhar e o redimensiona como máquina de visão? Ora, para responder a isso, um caminho pode ser pensar que, se está previsto um uso, está pressuposta uma certa prática social e cultural dos usuários. E, nesse horizonte de indagação, reecontramos, se não aquele sentido baudryniano de um vetor ideológico e psicológico subjacente, o sentido foucaultiano de uma certa disciplina prevista no uso do aparato. Então, as questões sobre o Oculus Rift, enquanto dispositivo, se configuram assim: qual o uso previsto do Oculus Rift e como esse uso traduz uma relação disciplinar do olhar, subjacente à passagem da máquina de ver para a máquina de visão? E ainda: se há um uso previsto, quais seriam os meios de jogar com esse uso e, com isso, profaná-lo (no sentido de Agamben), desarticulando-o dos fins e fazendo-o retornar a um estado de meio puro?

No que diz respeito à primeira questão, o que nos cabe perguntar é: como o Oculus Rift se apresenta em suas articulações discursivas e materiais e o que, através dessas articulações, ele promete ao usuário? Parte da resposta já encontramos na descrição que apresentamos acima. Há uma produção de realidade virtual que vai além do encantamento com o 3D no cinema tradicional, se tomarmos como exemplo a resolução e naturalidade na reprodução dos movimentos capturados. Há também um apelo à ideia de que a mobilidade do corpo durante a espectatorialidade é algo em si desejável e que promete novas possibilidades. 
Dado o cumprimento dessas promessas, feitas não apenas no terreno do marketing voltado para o Oculus Rift, mas no campo da inserção discursiva das descrições sobre os produto, temos posteriormente uma reduplicação desses discursos no modo como os usuários se comportam durante a experiência visual. $O$ interesse de ver a novidade se traduz em um prazer por ver-se movendo a cabeça e mesmo o tronco, buscando não apenas acompanhar o rudimento de narrativa que está dado nos demos (animações feitas com o intuito de divulgar o aparelho), mas, sobretudo, ver-se empoderado quanto à capacidade de mover a cabeça e o corpo, e não apenas os olhos. E isso é claro quando observamos os diversos videos do Youtube (figura 2), mostrando pessoas se surpreendendo com a capacidade que têm de se moverem e seu movimento ser reconhecido.

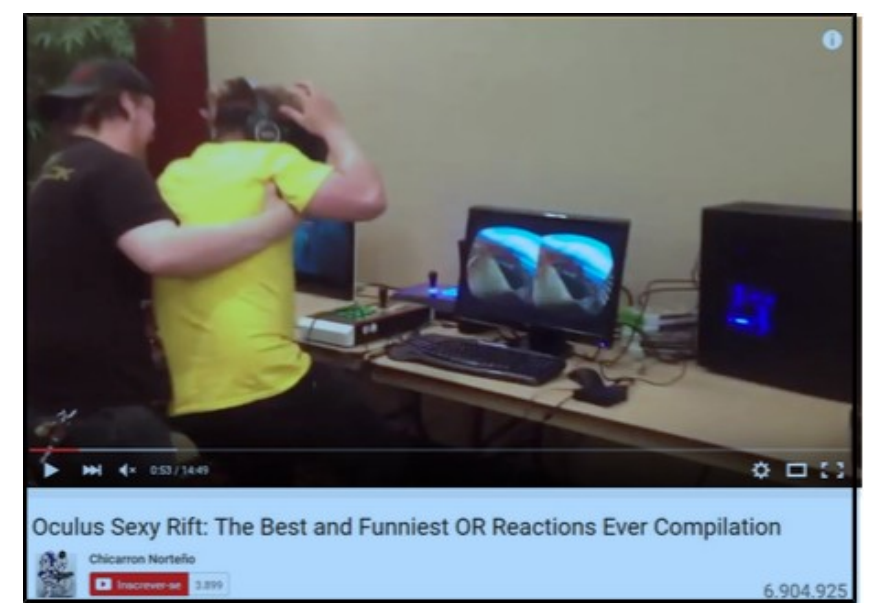

Figura 2 - Uma das muitas compilações de experiências de usuários do Oculus Rift que não sabiam o que esperar. Fonte: YouTube ${ }^{10}$.

Essa ampliação da capacidade de fruição, para além da movimentação do olho para uma mobilização do corpo ou parte dele, poderia fazer pensar que o espectador baudryniano teria sido superado e que está em jogo um outro processo de subjetivação que não o da identificação especular. Talvez essa máquina de ver contenha a potencialidade disso, de permitir explorar outras potencialidades, ainda que a maioria de seus produtos reforcem o seu

\footnotetext{
${ }^{10}$ Disponível em: $<$ https://www.youtube.com/watch?v=INDKNA7kXoo $>$. Acesso em: 30 nov. 2015. 
uso previsto. Mas quais são (ou quais poderiam ser) os vetores inaugurados por essa nova modalidade de realidade virtual que poderiam abrir novas linhas de subjetivação?

\section{Potência, profanação e subjetivação}

Na medida em que uma máquina de ver, como o Oculus Rift, traz consigo um uso default previsto de hardware e software, o qual é sinalizado pelas diversas redes discursivas e materiais que o atravessam, podemos dizer que ele, como qualquer outro dispositivo, estabelece o que seriam, segundo Deleuze, "linhas duras" normatizadoras (DELEUZE, 1988). Normatizadoras no sentido de que, criando usos típicos, sua lógica operatória cria enquadramentos, gerando comportamentos adaptativos: cada um quer fazer o seu uso (produzindo e interagindo), mas da maneira prevista nos demos e nos discursos publicitários.

Como estabelecem linhas duras do dispositivo, esses enquadramentos estão calcados em dicotomias específicas: três dimensões versus duas; recepção individual versus coletiva; mover(-se) versus ver; corpo móvel/dinâmico versus corpo fixo/estático etc.

Se quisermos pensar para além das dicotomias estratificantes e, com isso, ir além do uso previsto do dispositivo Oculus Rift, teríamos que apontar para outro horizonte: o dos usos vetorizados pela potência (AGAMBEN, 2007) Agamben) ou pela subjetivação (DELEUZE, 1988). Se pudermos pensar em possibilidades rizomáticas (DELEUZE e GUATTARI, 1997) de uso do dispositivo Oculus Rift, isto é, se apontarmos para as possibilidades de um ponto, estratificado no uso, poder se conectar com qualquer outro, apontando para fora das dicotomias, poderíamos pensar em usos profanatórios desse dispositivo. Pensemos em uma dicotomia específica, prevista no uso default do Oculus: a mobilidade do corpo em oposição à fixidez da espectatorialidade comum própria aos meios audiovisuais tradicionais.

Antes disso, porém, pensemos naquilo que a dicotomia, em si, prevê em termos de uso e, com isso, estratifica em termos de apropriação produtiva e/ou recepção. Esse corpo em movimento na espectatorialidade dos produtos feitos para o Oculus Rift, quando apenas oposto à fixidez espectatorial, cria, certamente, um novo modo de experiência estética. Isto poderia levar a pensar, em um primeiro momento (como apontamos acima), que estaríamos nos distanciando daquele olhar renascentista (sem falar de sua posição especular, que é seu contraponto) pensado em relação ao cinema na tradição de Baudry. Afinal, rompida a 
passividade de um olhar fixo, supostamente haveria a ruptura de uma soberania do olhar desse sujeito que, identificado com a câmera, está fixo. O seu oposto, a mobilidade inerente ao próprio dispositivo de realidade virtual com movimento corporal monitorado e que afeta a imagem $^{11}$, nesse sentido, promete quebrar a lógica que transforma máquina de ver em uma máquina de visão pós-cinematográfica (em um sentido específico de uma visão, por assim dizer, pós-renascentista).

Será, porém, isso mesmo o que ocorre? Apenas a mobilidade em oposição à fixidez cria, por si mesma, as condições de romper com a dicotomia estratificante, instaurada na essência do dispositivo, como linha dura? Se pensarmos que o corpo permanece ainda sem deslocar-se para além da linha dura fixidez/mobilidade, diríamos que não. Afinal, mesmo que agora móvel, o corpo ainda permanece sob o comando de uma instância alheia: a da narrativa ou, de modo mais geral, a do controle de um sujeito que, para vias de fruição do conteúdo narrativo, mobiliza-se. Cumpre-se a promessa de um corpo móvel, mas permanece a oferta de um corpo que se move conforme um sujeito que, mobilizando-se, permanece soberanamente móvel. Neste sentido, rompe-se a passividade da caverna baudryniana (o corpo fixo na sala de cinema), mas não a soberania de um sujeito que olha o mundo conforme um horizonte de controle, acrescido agora de um controle de seu próprio corpo. Poderíamos pensar que, enquanto o corpo não entra em novas relações, não haverá propriamente subjetivação, no sentido deleuzeano, mas protocolo de ação subjetiva conforme fins estabelecidos: narrativos, de jogabilidade, de imersão. A mobilidade, portanto, nesse sentido, não quebra a dicotomia estratificante; antes, a perpetua.

Pensar nas potências de uso de um dispositivo como o Oculus Rift para além das dicotomias fixidez/mobilidade do corpo seria pensar, então, em novos usos dos corpos, usos que questionem, flexibilizem a soberania de uma mentalidade no controle do seu próprio corpo. O que estaria na potência do meio, do dispositivo Oculus, que permitiria uma ruptura em relação a um uso previsto, apontando para um novo uso do corpo quebrando a dicotomia estratificante?

Uma experiência interessante, nesse sentido, pode ser a instalação Gender Swap Experiment do grupo BeAnotherLab. A instalação consiste em dois headsets do primeiro

\footnotetext{
${ }^{11}$ Podemos, naturalmente, falar da possibilidade do movimento mesmo nos meios audiovisuais "clássicos". A mudança prometida é que a mobilidade afete diretamente a própria imagem, que se modifica - dentro de limites de um "quadro expandido", por assim dizer - de acordo com os movimentos do corpo.
} 
protótipo do Oculus Rift, o DK1, duas webcams, um computador e um espelho (figura 3). Ou seja, as imagens capturadas pela webcam acoplada no headset do usuário 1 são transmitidas, em tempo real e via computador, para a tela do DK1 do usuário 2 e vice-versa. Segundo a descrição no site do próprio grupo,

\begin{abstract}
A experiência dura de 10 a 15 minutos aproximadamente e consiste de interações dos usuários entre si e com assistentes; usamos diferentes tipos de feedback multissensorial, incluindo espelhos para reforçar a ilusão. Uma vez que os usuários tenham aceitado seus novos corpos, a experiência culmina no ponto em que um usuário pode ver a si mesmo da perspectiva do outro. O sistema funciona como uma plataforma para teorias de gênero e queer ou como uma experiência terapêutica ${ }^{12}$.
\end{abstract}

Se pudermos pensar esse uso como um uso vetorizado por uma potência inerente ao Oculus Rift, mas não necessariamente contemplada nos usos atuais e previstos que atualizam apenas aspectos limitados desse dispositivo, podemos pensar, com Agamben, nessa experiência como uma possível profanação.

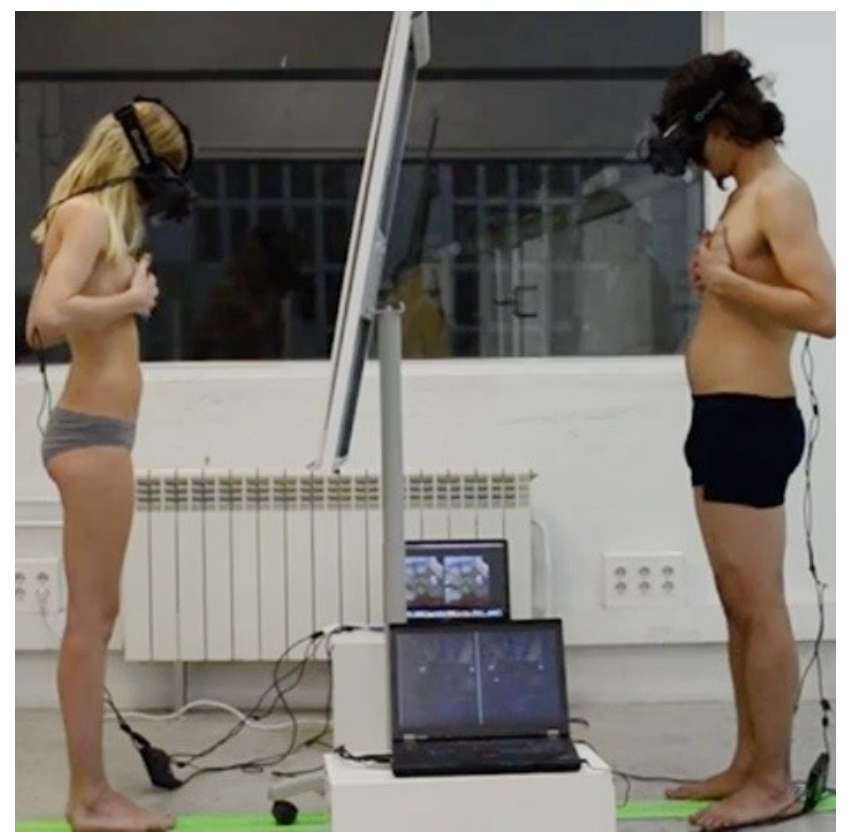

Figura 3 - Instalação Gender Swap (troca de sexo). Fonte: página do projeto na internet ${ }^{13}$.

\footnotetext{
${ }^{12}$ Tradução livre de: "The experience last from $10-15$ minutes approximately and it consists of users' interactions between them and with assistants; we use different multi-sensory feedback including mirrors to reinforce the illusion. After the users have accepted this new body of their own, the experience culminates when users can see themselves from the perspective of the other. The system works as a research platform of gender and queer theories as well as a therapeutic experience".

${ }^{13}$ Disponível em: <http://www.themachinetobeanother.org>. Acesso em 2 mar. 2016.
} 
Agamben parte, por um lado, de uma definição de "profanação", que remonta aos juristas romanos, segundo a qual profanar significaria restituir ao uso comum aquilo que teria sido separado para o uso sagrado e, por outro, da intuição de Walter Benjamin de acordo com a qual o capitalismo restitui o sagrado na mercadoria, o que levaria a pensar que, no capitalismo, já que tudo é revestido do caráter de sagrado (fetichizado no próprio ato de ser produzido e na própria lógica de circular como mercadoria), a profanação seria impossível. É nesse sentido, de uma apropriação de meios (materiais ou imateriais) está desde já marcado por um uso previsto, marcado pelos seus fins, que podemos dizer que o estabelecimento de um dispositivo material está, de antemão, marcado por um uso e, visto como tal, seria impossível profaná-lo.

Para Agamben, no entanto, a possibilidade de profanação (ou de profanações parciais) está no jogo, não apenas nos usos novos. Jogar, nesse contexto, implicaria tornar um meio desconectado dos fins (usos) previstos; significaria, em última instância, recolocar o uso de tal modo que seja vetorizado pela potência do meio, não apenas por atos que atualizem seus usos previstos.

Nesse sentido, é relevante distinguir com Agamben duas estratégias:

\begin{abstract}
É preciso, nesse sentido, fazer uma distinção entre secularização e profanação. A secularização é uma forma de remoção que mantém intactas as forças, que se restringe a deslocar de um lugar a outro. Assim, a secularização política de conceitos teológicos (a transcendência de Deus como paradigma do poder soberano) limita-se a transmutar a monarquia celeste em monarquia terrena, deixando, porém, intacto o seu poder. A profanação implica, por sua vez, uma neutralização daquilo que profana. Depois de ter sido profanado, o que estava indisponível e separado perde a sua aura e acaba restituído ao uso. Ambas as operações são políticas, mas a primeira tem a ver com o exercício do poder, o que é assegurado remetendo-o a um modelo sagrado; a segunda desativa os dispositivos do poder e devolve ao uso comum os espaços que ele havia confiscado. (AGAMBEN, 2007, p.60-61, grifos nossos).
\end{abstract}

Então, se transportarmos a metáfora do jogo para o nosso caso, vemos com mais clareza que não basta reverter os pólos das dicotomias estratificantes. Em específico, mobilizar o corpo não implica, por si só, redesenhar a lógica da subjetividade inerente à espectatorialidade dos meios audiovisuais clássicos (sem a possibilidade da mobilidade dos corpos afetarem a imagem). Nesse sentido, se um dispositivo de realidade virtual como o Oculus Rift afeta a fixidez do corpo, no máximo o faz no sentido de uma secularização: o 
corpo se move, mas a soberania dos sujeitos sobre os corpos permanece. Uma via de profanação, no sentido específico dessa dicotomia fixidez/mobilidade, estaria, antes, na ruptura da própria soberania. A simulação de estar em outro corpo, tal como vemos no Gender Swap Experiment aponta para um potencial do Oculus que não estava prevista no seu uso default: a ruptura, lá onde seria até mesmo imprevista (pois o discurso de novidade é justamente prometer controle sobre a imagem através do corpo) a perda dos poderes sobre o próprio corpo, isto é, uma flexibilização de linhas duras do dispositivo, quiçá a possibilidade de uma linha de fuga. Se não tanto, há pelo menos nesse exemplo um horizonte aberto: tornar o dispositivo material um meio para outras potencialidades não atualizadas no uso previsto.

\section{Considerações finais}

Juntamente com outros parâmetros em default, a nova geração de dispositivos de realidade virtual, inaugurada com o Oculus Rift, já surge com uma tendência que possibilita "linhas de fuga", para usar a expressão de Deleuze, que seus antepassados não conseguiram oferecer, quando, nos anos 1990, consoles e visores de realidade virtual eram programas fechados em si mesmos, incompatíveis com outros sistemas operacionais, ocasionando uma implosão da tecnologia em seus dispositivos volumosos, desconfortáveis e tecnologicamente imaturos.

No entanto, como tentamos colocar, no âmbito dessas potências, raras são aquelas que vetorizam a subjetividade do usuário para fora dos usos previstos nos dispositivo, no momento do uso. Ou seja, levem-no a pensar/questionar sua própria condição de sujeito diante da imagem. Tentamos, a partir do experimento Gender Swap, oferecer uma ideia de como tal profanação seria possível e como uma via de subjetivação potencialmente se abriria. Nesse caso, a profanação ocorreria por meio da perda de soberania do usuário como sujeito, em, ao menos, três momentos. No primeiro, quando se opera um corpo alheio, quando a promessa dos dispositivos de realidade virtual é a descorporificação. No segundo, quando o corpo dos usuários é trocado, este passa a ser objeto da curiosidade e das vontades do outro. E, ainda, uma vez que a ilusão de se estar no corpo alheio depende da sincronização dos movimentos (por isso o uso do espelho), perde-se a liberdade de movimento, condição que vai de encontro à mensagem transmitida pela publicidade do Oculus Rift. 
Pensamos (e este horizonte nos guia) que a realidade virtual, como ferramenta para o artista, pode colocar em jogo dicotomias interessantes que apontem para o pensar sobre uma outra condição do realismo afetivo, ancorada nas discussões filosóficas sobre o dispositivo: este como via de acesso a um conhecimento dos sujeitos e de suas relações com os meios e suas imagens.

\section{Referências}

BAIO, Cesar. Máquinas de Imagem: Arte, Tecnologia e Pós-Virtualidade. São Paulo: Annablume, 2015.

AGAMBEN, Giorgio. O que é um dispositivo? Outra travessia, Florianópolis, n. 5, p. 9-16, 2005. Disponível em: <https://periodicos.ufsc.br/index.php/Outra/article/view/12576/11743>. Acesso em: 11 mai. 2015.

Profanações. Trad. Selvino J. Assmann. Perdizes: Boitempo Editorial, 2007.

BAUDRY, Jean-Louis [1970]. Cinema: efeitos ideológicos produzidos pelo aparelho de base. Trad. Vinícius Dantas. In: XAVIER, Ismail. (Org.). A experiência do cinema: antologia. Rio de Janeiro: Graal, 2000.

DELEUZE, Gilles. Foucault. São Paulo: Brasiliense, 1988.

DELEUZE, Gilles; GUATTARI, Félix. Mil platôs: capitalismo e esquizofrenia. São Paulo: Editora 34, 1997.

FOUCAULT, Michel [1977]. Le jeu de Michel Foucault. In: Dits et écrits. Paris, Gallimard, p. 298-329, 1994.

KESSLER, Frank. Notes on Dispositif. Utrecht: Media Research Seminar, 2007. Disponível em: <http://www.let.uu.nl/ Frank.Kessler/personal/Dispositif\%20Notes11-2007.pdf >. Acesso em: 27 mai. 2016.

LACAN, Jacques [1949]. O estádio do espelho como formador da função do eu tal como nos revela a experiência psicanalítica. In: Escritos, p. 96-103. Rio de Janeiro: Jorge Zahar Ed., 1998.

SCHOLLHAMMER, Karl Erik. Realismo afetivo: evocar realismo além da representação. In: Estudos de literatura brasileira contemporânea. n.39, jan./jun. 2012, p. 129-148.

SHAVIRO, S. Emotion Capture: Affect in Digital Film. In: Projections 2.1, 37-55, 2007a. 
The post-cinematic affect. Washington e Winchester: O-Books, $2010 \mathrm{~b}$.

XAVIER, Ismail. O discurso cinematográfico: a opacidade e a transparência. São Paulo: Paz e Terra, 2005. 